УДК 339.9

ББК 65.5

ИНТЕРНАЦИОНАЛИЗАЦИЯ ДЕЛОВОЙ АКТИВНОСТИ КАК ВАЖНАЯ ЧЕРТА ГЛОБАЛИЗАЦИИ

А. В. ДАНИЛЬЧЕНКО

adanilchenko@bntu.by

доктор экономических наук, профессор,

декан факультета менеджмента, маркетинга и предпринимательства

Белорусский национальный технический университет

Минск, Республика Беларусь

Т. А. ПРОЦ

tatiana prots@mail.ru

преподаватель кафедры «Маркетинг»

Белорусский национальный технический университет

Минск, Республика Беларусь

Статья посвящена изучению интернационализащии деловой активности. Рассматривается планируемые направления развития экспортной политики Беларуси. Выявляются особенности процесса интернационализации Китайской Народной Республики.

Ключевые слова: интернационализация, развитие, интеграция, инвестиции.

\title{
INTERNATIONALIZATION OF BUSINESS ACTIVITY AS IMPORTANT FEATURE OF GLOBALIZATION
}

\author{
A. V DANILCHENKO \\ Doctor of Economics, Full Professor, \\ Dean of the Faculty of Management, Marketing and Entrepreneurship \\ Belarusian National Technical University \\ Minsk, Republic of Belarus \\ T. A. PROTS \\ Master of Economics. , the teacher of the department "Marketing" \\ Belarusian National Technical University \\ Minsk, Republic of Belarus
}

The article is devoted to the study of the internationalization of business activity. Discusses the planned directions of development of export policy of Belarus. Identifies features of the process of internationalization of the Republic of China.

Key words: internationalization, development, integration, investment.

\section{ВВЕДЕНИЕ}

Интернационализации деловой активности - разнонаправленный процесс. Традиционно он понимается как активизация экспортной инвестиционной деятельности компаний на зарубежных рынках при институциональной поддержке и лоббировании интересов национальным государством. Со стороны принимающей страны это рассматривается либо как привлечение иностранного капитала и технологий, либо как ограничение деятельности иностранных компаний. При нехватке внутренних инвести- 
ций, неразвитости отдельных секторов и отраслей народного хозяйства проводится государственная политика стимулирования деловой активности иностранных компаний. В противоположном случае имеет место политика селективного протекционизма и/или реализуются программы замещения импорта [1, с. 188].

Внешнеэкономическая политика, сформулированная в рамках Научного прогноза, предполагает осуществление многовекторной внешней политики Республики Беларусь и достижение устойчивого роста экспортного потенциала белорусской экономики с одновременным обеспечением положительного сальдо во внешнеэкономической деятельности. «... В настоящее время в экономической науке все большее значение приобретает изучение сотрудничества между хозяйственными субъектами как основы повышения их конкурентоспособности. При этом акцент делается на том обстоятельстве, что смитианские взгляды на рыночную ситуацию, как поле конкурентной борьбы всех со всеми сегодня безнадежно устарели» [2].

Основной целью развития внешнеэкономических отношений Республики Беларусь является снижение до минимума внешнеэкономических угроз на основе эффективного участия в международном разделении труда, использования конкурентных преимуществ страны, применения механизмов международных интеграционных объединений и снижения зависимости от традиционных экспортных позиций и рынков за счет диверсификации товарной номенклатуры [3].

В национальной программе поддержки и развития экспорта на 2016-2020 годы выделены 5 приоритетных направлений, по которым государство буде работать в ближайшие годы. Среди них: соответствие белорусской продукции соответствующим нормам и стандартам в области качества, сертификация и обеспечение иных условий для ее доступа на внешние рынки; создание альянсов с крупными региональными производителями, вхождение вместе с ними в международные производственные цепочки; совершенствование инфраструктуры контроля качества, проведения испытаний и оценки соответствия продукции; стимулирование производителей товаров к расширению товарной номенклатуры.

В Программе «экспорт Беларуси» главным механизмом реализации и неотъемлемым элементом является Дорожная карта. В последнее время учеными- экономистами широко используются понятия такие как технологический форсайт, бизнеспланирование и построение технологических дорожных карт. Все перечисленные понятия связаны с планированием и прогнозированием развития действий предприятия. Дорожная карта представляет собой пошаговую инструкцию и направление движения, какого-либо товара, группы товаров/услуг, предприятия в целом. Бизнес-план - план, программа осуществления бизнес-операции, действий фирмы, содержащая сведения о фирме, товаре, его производстве, рынках сбыта, маркетинге, организации операций и их эффективности [4]. Форсайт - это метод долгосрочного прогнозирования развития, основанный на опросе экспертов.

Дорожные карты отличаются от бизнес-планов тем, что имеют несколько сценариев и направлений развития ситуаций. Дорожные карты имеют более широкую сферу применения и актуальны на современном этапе.

Картирование целесообразно начинать с форсайта. Важно определить видение мира и место страны, рыночную позицию Беларуси и конкурентные преимущества предприятий в долгосрочной перспективе (15-20 лет). После этого определяются потребности и необходимые изменения в ближайшем будущем (3-5 лет) и по результатам прогноза составляются планы мероприятий и формируется дорожная карта. 
Таблица 1 - Основные отличительные черты бизнес-плана и дорожной карты

\begin{tabular}{|l|l|l|}
\hline Критерий & Бизнес-план & Дорожная карта \\
\hline Сфера применения & $\begin{array}{l}\text { Внутрифирменное планиро- } \\
\text { вание }\end{array}$ & $\begin{array}{l}\text { Государство в целом, отдель- } \\
\text { ные отрасли предприятия, } \\
\text { отдельные виды товаров и } \\
\text { услуг или их группы }\end{array}$ \\
\hline Сроки планирования & $1-5$ лет & $5-10$ лет \\
\hline $\begin{array}{l}\text { Рабочая группы разработчи- } \\
\text { ков }\end{array}$ & $\begin{array}{l}\text { Руководитель и сотрудники } \\
\text { подразделений предприятия }\end{array}$ & $\begin{array}{l}\text { Специалисты разных направ- } \\
\text { лений, институты }\end{array}$ \\
\hline Цель & $\begin{array}{l}\text { Планирование хозяйствен- } \\
\text { ной деятельности предприя- } \\
\text { тия }\end{array}$ & $\begin{array}{l}\text { Информационная поддерж- } \\
\text { ка процесса принятия управ- } \\
\text { ленческих решений по разви- } \\
\text { тию объекта картирования }\end{array}$ \\
\hline Форма представления & Попунктный план & Графический план-сценарий \\
\hline
\end{tabular}

Источник: разработка автора

Дорожная карта как элемент Программы «Экспорт Беларуси» направлена на достижение роста, развития и диверсификации национального экспорта, в первую очередь, инновационного и высокотехнологичного, а также позволит повысить эффективность действующей в Республике Беларусь системы государственной поддержки экспорта до уровня лучших мировых практик.

Реализация мероприятий Дорожной карты будет способствовать увеличению объемов экспорта продукции [3].

Для определения направлений развития экономики Беларуси целесообразно обратиться к опыту других стран, которые достигли больших успехов в данном направлении. Примером удачной реализации политики интернационализации, а так же траснационализации может выступить Китайская Народная Республика, которая занимает высокие позиции в мировых рейтингах.

\section{РЕЗУЛЬТАТЫ И ИХ ОБСУЖДЕНИЕ}

В этой связи, стоит подробнее рассмотреть использование международного опыта в области развития экспорта на примере Китайской Народной Республики, а так же причины, мотивация и стратегии интернационализации бизнеса.

Использование международного опыта и национальных научных разработок в области экспорта необходимы для обеспечения баланса в программе теоретических и прикладных методов по организации работы на экспортном направлении и принципиально новых подходов в этой области, основанных на лучших мировых достижениях [3].

Для более объективной картины следует обратить внимание на происходящие процессы в мировой экономике. По данным Доклада ЮНКТАД о мировых инвестициях, в 2016 г. рост мировой экономики составил всего лишь 2,2\%, что является самым низким показателем со времен 2009 года. Одной из основных причин замедления мирового роста доклад называет длительный период низкой инвестиционной активности. В последние годы для многих стран характерно заметное снижение объемов частных и государственных инвестиций. В странах-экспортерах сырьевых товаров в ответ на резкое снижение доходов правительства сокращают объем крайне необходимых инвестиций в инфраструктуру и социальные службы. В то же время, в большинстве развитых стран, а также во многих крупных развивающихся странах и странах с переходной экономикой отмечается заметное снижение темпов роста производительности труда. 
Поскольку спрос, инвестиции, торговля и производительность тесно взаимосвязаны, длительный период замедленного мирового роста может так и не прекратиться, если не предпринять согласованные политические усилия по оживлению инвестиций и стимулированию восстановления роста производительности труда. В докладе отмечается, что во многих странах для поддержки роста по-прежнему слишком широко используется кредитно-денежная политика [5].

По данным Доклада, Китайская Народная Республика по-прежнему занимает второе место в мире и является крупнейшей среди развивающихся стран получателем прямых иностранных инвестиций 128 млрд. долл. в 2015г. и 183 млрд. долл. в 2016 г. [7].

Этот потенциал инвестиционного сотрудничества реализуется благодаря умелой политике государства по стимулированию иностранных вложений. Характерная черта такой политики - предоставление предприятиям с иностранным участием специальных льгот. Это свойственно начальному периоду политики открытости, когда Китай воспринимался большинством инвесторов как высокорискованный рынок, а перестройка хозяйственной системы КНР только набирала обороты. По мере активизации притока иностранного капитала и углубления рыночных реформ происходит постепенное выравнивание режимов хозяйствования для национальных и иностранных инвесторов. Но делается это не столько путем лишения предприятий с иностранным участием преференциального статуса, сколько за счет распространения аналогичных условий на китайские предприятия. Как и в случае с внешней торговлей, китайское руководство не спешит либерализировать режим иностранного инвестирования. Специальные льготы получают прежде всего предприятия в приоритетных сферах материального производства (машиностроение, электроника, сельское хозяйство и т. д.). Напротив, иностранные инвестиции в сферу финансовых услуг и розничной торговли были разрешены только в нескольких городах наиболее развитого приморского пояса Китая.

В КНР определены три укрупненные группы китайских компаний, которые должны войти в состав 500 крупнейших ТНК мира [8, с. 18-19].

Правительство КНР проводит политику активной, но селективной поддержки экономической транснационализации [1, с. 154]. Экономическая траснационализация это наиболее зрелая стадия интернационализации экономической деятельности, характеризующаяся перемещением капитала через границы страны происхождения, которое выражается в формировании международных по характеру своей деятельности, но национальных по сохраняемому над акционерным капиталом контролю организационных бизнес-структур [13].

В последние годы наблюдается активный рост потребления энергоресурсов в Китае, в это же время собственными ресурсами страна не обеспечена в полной мере, поэтому китайские компании приобретают зарубежные добывающие или права на эксплуатацию месторождений. Одно из приоритетных направлений экономической транснационализации КНР выражается в широкомасштабном инвестиционном контроле над ресурсно-сырьевой базой зарубежных стран. Инвестиционная активность в данном направлении распространяется независимо от географической близости стран и регионов. В сфере внимания находятся страны с разным уровнем социально-экономического развития [1]. Основные направления транснационализации КНР представлены на рисунке 1 . 


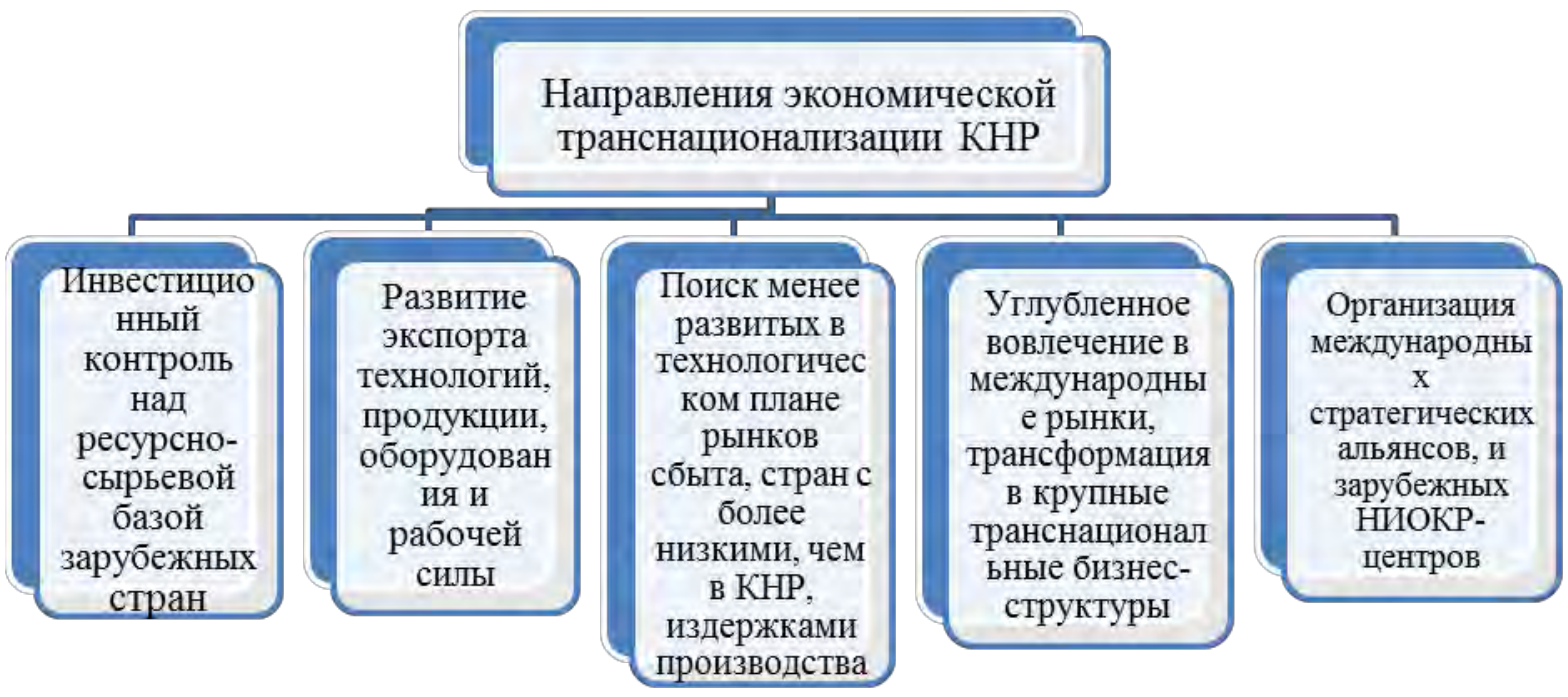

Рисунок 1 - Направления экономической транснационализации Китайской Народной Республики

Источник: разработка автора на основе [1, с 157-160].

Из 500 крупнейших ТНК, по версии «Fortune Global 500», 104 китайских компаний вошли в рейтинг в 2016 г. В топ-10 на 2-м месте - корпорация «State Grid» (электроэнергетика), выручка - 315,199 млрд. долл., на 3-м месте - «Sinopec Groupe», выручка - 267,518 млрд. долл. Четвертое место заняло предприятие нефтеперерабатывающей промышленности «China National Petroleum» с выручкой - 262,573 млрд. долл. США [9]. Нужно отметить, что в экономике КНР наблюдалось снижение экономического роста по сравнению с 2016 и 2015 гг.

Немаловажным фактом так же является то, что инвестиционная активность Китая направлена на организацию международных стратегических альянсов и зарубежных НИОКР- центров. Стадии экономической траснационализации китайских компаний по организации зарубежных НИОКР- центров представлены на рисунке 2.

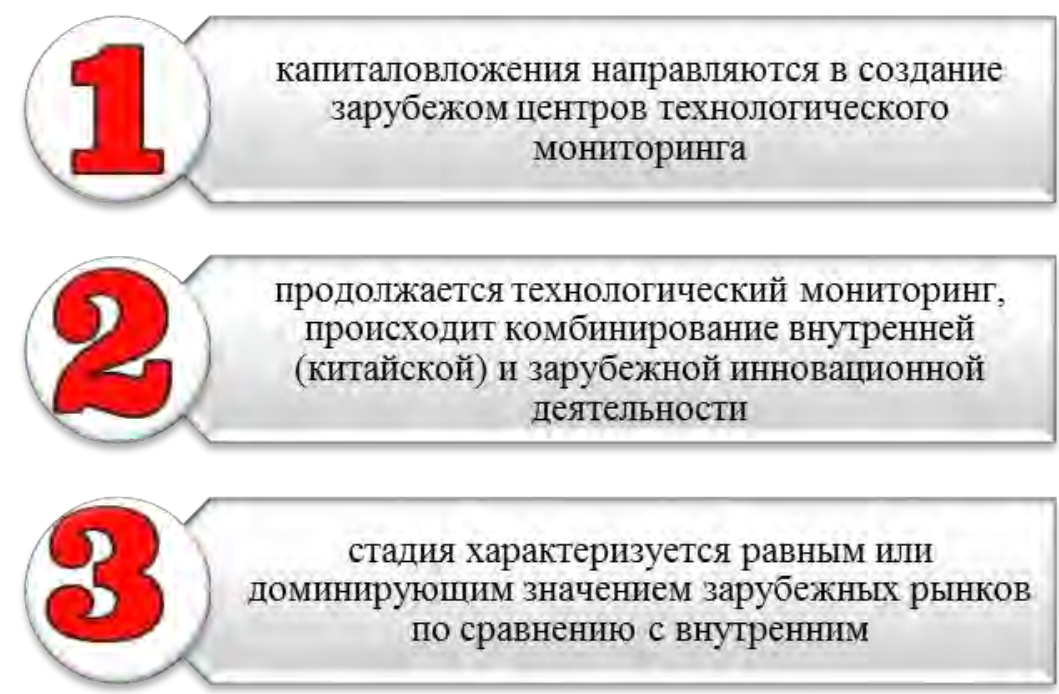

Рисунок 2 - Стадии экономической траснационализации компаний КНР Источник: разработка автора на основе [1, с. 170-175]. 
Из всего вышесказанного можно сделать вывод, что интернационализация китайской деловой активности идет высокими темпами. Этому содействуют различные государственные программы, политика страны по привлечению инвестиций, а также акционирование государственных предприятий.

\section{ВЫВОДЫ}

Анализируя опыт Китайской Народной Республики и цели Республики Беларусь в направлении интернационализации деловой активности компаний, можно сделать вывод, что для устойчивого развития необходимо взаимодействие как со стороны государства и государственных институтов, так отдельных предприятий и отраслей. Предприятия со своей стороны должны производить конкурентоспособную, высокотехнологичную продукцию, востребованную на внутренних и внешних рынках. Государство должно разрабатывать и реализовывать эффективные программы по содействию развитию интернационализации отечественных предприятий, а также проводить политику по привлечению прямых иностранных инвестиций в страну. Создание благоприятного инвестиционного климата - неотъемлемая часть деятельности.

Как сказано в Национальной программе поддержки и развития экспорта на 20162020 гг., использование Дорожных карт направлено на развитие и диверсификацию экспорта. Одним из направлений диверсификации экспорта может стать инвестирование предприятий или отраслей за границей. При картировании целесообразно рассмотреть варианты движения как отдельных товаров и/или услуг, так и экспорт инвестиций. Как показывает опыт Китая, использование программ по выводу компаний на лидирующие мировые позиции имеет свой положительный результат.

В следующую программу развития белорусской экономики можно включить следующие направления:

1. Вовлечение предприятий в международные рынки с последующей их трансформацией в транснациональные структуры.

2. Создание базы для зарубежных НИОКР- центров.

3. Создание зарубежных объектов производственного назначения.

4. Обеспечение экономической безопасности и защиты от негативных изменений международной конъюнктуры.

Процесс интернационализации требует тщательной подготовки и планирования. Для разработки программ развития необходимо учитывать мнение и интересы как отдельных предприятий и их опыт, так и государственные интересы в целом.

С учетом того, что большая часть белорусских участников внешнеэкономической деятельности являются предприятиями с государственным капиталом, то интеграция и интернационализация должна проходить одновременно на межгосударственном и микроэкономическом уровнях.

\section{СПИСОК ИСПОЛЬЗОВАННЫХ ИСТОЧНИКОВ}

1. Данильченко, А. В. Интернационализация деловой активности стран и компаний / А. В. Данильченко, Е. В. Бертош, О. Ф. Малашенкова. - Минск : БГУ, 2015. - 295 с.

2. Солодовников, С. Ю. Влияние расширения Таможенного союза на экономическую конкурентоспособность Беларуси и Армении / С. Ю. Солодовников, Т. В. Иванова // Экономическая наука сегодня, 2016 - Вып. 4. - С. 188.

3. Национальная программа поддержки и развития экспорта на 2016-2020 годы [Электронный ресурс]: постановление Совета Министров Республики Беларусь, 
10.08.2016 г., № 604 // Интернет-портал Республики Беларусь. - Режим доступа: http://www.government.by/upload/docs/fileaff83a3fc04eb9c0.PDF. - Дата доступа 03.10.2017.

4. Райзберг, Б. А. Современный экономический словарь. 5-е изд., перераб. и доп / Б. А. Райзберг, Л. Ш. Лозовский, Е. Б. Стародубцева. - М.: ИНФРА-М, 2007. - 495 с.

5. World Economic Situation Prospects. Пресс-релиз [Электронный ресурс]. - Peжим доступа: https://www.un.org/development/desa/dpad/wp-content/uploads/sites/45/2017 wesp gpr ru.pdf. - Дата доступа 04.10.2017

6. Конференция Организации Объединенных Наций по торговле и развитию ЮНКТАД.: Доклад о мировых инвестициях, 2016 г. "Гражданство" инвесторов: вызовы политики“ Основные тенденции и общий обзор.- Женева: ООН, 2016.

7. Конференция Организации Объединенных Наций по торговле и развитию ЮНКТАД.: Доклад о мировых инвестициях, 2017 г. «Инвестиции и цифровая экономика» Основные тенденции и общий обзор.- Женева: ООН, 2017. (на английском языке)

8. Авдукшин, Е. Ф. Конкурентоспособность китайской экономики в глобализирующемся мире / Е. Ф. Авдушкин // Экономика и политика. - 2007.- № 2.- С. 12-20.

9. Крупнейшие компании мира -2017. Fortune Global 500 [Электронный ресурс].- Режим доступа: http://global-finances.ru/krupneyshie-kompanii-mira-2017. - Дата доступа: 04.10.2017.

10. Семак, Е. А. Международный маркетинг : учебно-методический комплекс для студентов экон. фак., обучающихся по специальности 1-26 0202 «Менеджмент (по направлениям)» / Е. А. Семак, К. В. Якушенко. - Минск : БГУ, 2012.- 207c.

11. Данильченко, А. В. Предпосылки и стратегии интер-национализации венчурных структур / А. В. Данильченко, О. Ф. Малашенкова // Журн. междунар. права и междунар. отношений. - 2009.- № 2.- С. 73-78.

12. Данильченко, А. В. Современные направления развития теории интернационализации деловой активности предприятий /А. В. Данильченко, Д. С. Калинин / Труды факультета международных отношений : редкол. : В. Г. Шадурский (гл. ред.) [и др.]. Минск : Тесей, 2010. Вып. 1.

13. Данильченко, А. В. Теоретические основы транснационализации страны и предприятия / А. В. Данильченко, Д. С. Калинин / Беларусь и мировые экономические процессы: сб. науч. ст. вып. 8. / БГУ; редкол.: А. В. Данильченко (пред.) [и др.]. Минск, 2011. - 195 с.

\section{REFERENCES}

1. Danil'chenko, A. V. Internacionalizacija delovoj aktivnosti stran i kompanij / A. V. Danil'chenko, E. V. Bertosh, O. F. Malashenkova. - Minsk : BGU, 2015. - 295 s.

2. Solodovnikov, S. Ju. Vlijanie rasshirenija Tamozhennogo sojuza na jekonomicheskuju konkurentosposobnost' Belarusi i Armenii / S. Ju. Solodovnikov, T. V. Ivanova // Jekonomicheskaja nauka segodnja, 2016 - Vyp. 4. - S. 188.

3. Nacional'naja programma podderzhki i razvitija jeksporta na 2016-2020 gody [Jelektronnyj resurs] : postanovlenie Soveta Ministrov Respubliki Belarus', 10.08.2016 g., № 604 // Internet-portal Respubliki Belarus'. - Rezhim dostupa: http://www.government.by/up load/docs/fileaff83a3fc04eb9c0.PDF. - Data dostupa 03.10.2017

4. Rajzberg, B. A. Sovremennyj jekonomicheskij slovar'. 5-e izd., pererab. i dop / B. A. Rajzberg, L. Sh. Lozovskij, E. B. Starodubceva. - M.: INFRA-M, 2007. - 495 s. 
5. World Economic Situation Prospects. Press-reliz [Jelektronnyj resurs]. - Rezhim dostupa: https://www.un.org/development/desa/dpad/wp-content/uploads/sites/45/2017wesp_ gpr_ru.pdf. - Data dostupa 04.10.2017

6. Konferencija Organizacii Ob\#edinennyh Nacij po torgovle i razvi-tiju JuNKTAD.: Doklad o mirovyh investicijah, 2016 g. "Grazhdanstvo" investorov: vyzovy politiki“" Osnovnye tendencii i obshhij obzor. - Zheneva: OON, 2016.

7. Konferencija Organizacii Ob\#edinennyh Nacij po torgovle i razvi-tiju JuNKTAD.: Doklad o mirovyh investicijah, 2017 g. «Investicii i cifrovaja jekonomika» Osnovnye tendencii i obshhij obzor. - Zheneva: OON, 2017. (na anglij-skom jazyke).

8. Avdukshin, E. F. Konkurentosposobnost' kitajskoj jekonomiki v globalizirujushhemsja mire / E. F. Avdushkin // Jekonomika i politika. - 2007. - № 2. - S. 12-20.

9. Krupnejshie kompanii mira -2017. Fortune Global 500 [Jelektronnyj re-surs]. Rezhim dostupa: http://global-finances.ru/krupneyshie-kompanii-mira-2017. - Data obrashhenija 04.10.2017.

10. Semak, E. A. Mezhdunarodnyj marketing : uchebno-metodicheskij kom-pleks dlja studentov jekon. fak., obuchajushhihsja po special'nosti 1-26 0202 «Menedzh-ment (po napravlenijam)» / E. A. Semak, K. V. Jakushenko. - Minsk : BGU, 2012. - 207s.

11. Danil'chenko, A. V. Predposylki i strategii inter-nacionalizacii venchurnyh struktur / A. V. Danil'chenko, O. F. Malashenkova // Zhurn. mezhdunar. pra-va i mezhdunar. otnoshenij. - 2009. - № 2. - S. 73-78.

12. Danil'chenko, A. V. Sovremennye napravlenija razvitija teorii inter-nacionalizacii delovoj aktivnosti predprijatij /A. V. Danil'chenko, D. S.Kalinin / Trudy fakul'teta mezhdunarodnyh otnoshenij : redkol. : V. G. Shadurskij (gl. red.) [i dr.]. Minsk : Tesej, 2010. Vyp. 1.

13. Danil'chenko, A. V. Teoreticheskie osnovy transnacionalizacii strany i predprijatija / A. V. Danil'chenko, D.S. Kalinin / Belarus' i mirovye jekonomiche-skie processy: sb. nauch. st. vyp. 8. / BGU; redkol.: A.V. Danil'chenko (pred.) [i dr.]. - Minsk, 2011. - 195.

Статья поступила в редакичию 12 октября 2017 года. 